\title{
Empirical Models for Predicting Global Solar Radiation on the African Continent Based on Factors of Location and Season
}

\author{
Olabode M. Bamigbola*, Shola E. Atolagbe \\ Department of Mathematics, University of Ilorin, Ilorin, Nigeria \\ Email: *ombamigbola@unilorin.edu.ng
}

How to cite this paper: Bamigbola, O.M. and Atolagbe, S.E. (2021) Empirical Models for Predicting Global Solar Radiation on the African Continent Based on Factors of Location and Season. Open Journal of Modelling and Simulation, 9, 59-73.

https://doi.org/10.4236/ojmsi.2020.91004

Received: September 30, 2020

Accepted: January 18, 2021

Published: January 21, 2021

Copyright $\odot 2021$ by author(s) and Scientific Research Publishing Inc. This work is licensed under the Creative Commons Attribution International License (CC BY 4.0).

http://creativecommons.org/licenses/by/4.0/

\begin{abstract}
The importance of accurate knowledge about available global solar radiation in the design and development of various solar energy systems cannot be overemphasized. Most of the available models for predicting global solar radiation involve a plethora of input factors, some of which require special skills and equipment to measure. Such multi-factor models are complex and computationally demanding. To remove some burdens associated with such models, the use of simplified prototypes with reduced input factors has been proposed. It has been shown that a model with fewer input factors, that can be determined in a definite manner or whose attributes are directly observable, is often a better alternative. Therefore, the main object of this paper is to have models with a few variables that can easily be measured, developed for predicting global solar radiation. Two input factors, geographical location and season of the year, were considered. Using a 22-year interannual average daily insolation data from the database of the National Aeronautics and Space Administration (NASA) blended with the art of interpolation, empirical models were fashioned with the data for the five subregions of Africa. The results of the models' analysis indicate that the latitude component is the dominant locational factor. Furthermore, the new models exhibit optimal performance in comparison with existing models and constitute reliable predictive tools that are suitable for estimating global solar radiation for any practical application.
\end{abstract}

\section{Keywords}

Solar Radiation, Modelling, Empirical Data, Prediction, Interpolation

\section{Introduction}

Energy is invisible, nonetheless a driving force in the entire universe. It is a funda- 
mental input to any human activity [1]. Many types of energy exist; these include light energy, sound energy, solar energy, chemical energy and nuclear energy.

In the $19^{\text {th }}$ century, the use of fossil fuels enhanced rapid industrialization and modern civilization. However, excessive exploitation of fossil fuels directly and indirectly assists in global warming and other encumbrances which drive our planet towards a dark future. Today, technological advancements have enabled the development of alternative and renewable energy sources, one of which is solar energy.

Solar energy is free, it does not create pollution, and has helped man become less dependent on other more costly and damaging forms of energy [2]. Actually, solar energy is the most abundant renewable energy resource available in most regions of the world, and has become increasingly attractive as a renewable energy source.

Generally, people understand real-world phenomena better when they are represented symbolically. As such, modelling should be used not only to illustrate and deepen understanding, but also to predict real-world phenomena [3]. For instance, in the design and development of various solar energy systems, the estimation of solar radiation available is considered the most crucial issue [4]. The importance of models for solar radiation prediction is further emphasized because, in most cases, the density and number of solar radiation measuring stations cannot describe the necessary variability [5].

Most of the available models for predicting global solar radiation use some or even all of the following factors as input: sunshine data, solar declination, latitude, longitude, extraterrestrial radiation, relative humidity, soil temperature, temperature of the air, cloudiness, evaporation and precipitation among others. These factors require special skills and equipment to measure. In addition, models with multiple inputs have been shown to have insignificantly improved in accuracy compared with variants of the models in which fewer inputs are considered. Indeed, such variants are simpler to handle, not only in terms of computational convenience but also for ease of analysis, see Latunde et al. [6].

Therefore, the main objective of this paper is to develop models, with few input factors that can be used to predict global solar radiation. The new models introduced in this study require little computational effort, and the only information needed to use them is the knowledge of the longitude and latitude, in addition to the season at the location of interest.

\section{Global Solar Radiation}

Solar energy refers to sources of energy that can be directly attributed to the light of the sun or the heat that sunlight generates. It is also a fact that solar radiation is electromagnetic in nature. Global solar radiation, on the other hand, is the sum of the direct, diffuse and reflected solar radiations [7]. Radiation data for solar electric (photovoltaic) systems are presented in kilowatt-hours per square meter $\left(\mathrm{kWh} / \mathrm{m}^{2}\right)$. Direct estimates of solar energy may be expressed as watts per square meter $\left(\mathrm{W} / \mathrm{m}^{2}\right)$ while those for heating systems are usually measured in British thermal units per square foot $\left(\mathrm{Btu} / \mathrm{ft}^{2}\right)$. 


\subsection{Global Solar Radiation Models}

Several models have been proposed for estimating daily or monthly global solar radiation using different techniques such as geostationary satellite images, neural networks, time series methods, physical radiative transfer models, and stochastic weather methods. These are generally based on different types of data including meteorological and geographical data [8].

Meteorological data-based models depend on the most common meteorological elements including cloud cover, sunshine duration, temperature, and relative humidity, making them the most widely used models, especially the sunshine-based and temperature-based models [9]. The primary sunshine-based model can be traced back to Angstrom model, using sunshine duration and clear sky radiation data to estimate global solar radiation [10].

Many solar energy researchers have adopted Angstrom-Prescott-Page model as a baseline to further develop empirical models for predicting global solar radiation. One of these researchers is Falayi [11] who developed a number of multilingual regression equations to predict the relationship between global solar radiation with one or more combinations of the following weather parameters: clearness index, mean daily temperature, ratio of maximum and minimum daily temperature, relative humidity, and relative sunshine duration for Iseyin, Nigeria. $\mathrm{He}$ observed that incorporating sunshine-based model, temperature-based model and relative humidity-based model yielded better precision than either sunshine-based model, temperature-based model, or relative humidity-based model. Akpabio [12] obtained monthly mean daily basis model for the whole year, and for rainy and dry seasons for Onne, Nigeria. Others who considered the seasonal variation of monthly average daily global solar radiation in their models are Kolebaje and Mustapha [13].

In other locations in Africa, Soufi et al. [14] and Coulibaly \&Ouedraogo [15], in separate independent studies, calibrated sunshine-based models and hybrid parameter-based models using extraterrestrial solar radiation, sunshine fraction, clearness index, maximum temperature and sine of solar declination for several cities in Algeria and Burkina Faso respectively, and observed that hybrid models performed better than sunshine-based models.

It is pertinent to note that majority of the variables involved in most of the studies listed above require special skills and equipment to measure, whereas there are other variables which can be simply determined in a definite manner, and whose attributes are directly observable. Two of such factors and which are proposed for use in this study, are geographical location and seasonal variation.

\subsection{Factors of Global Solar Radiation}

Although the sun's energy output is fairly constant, the total solar radiation falling on the surface of the earth varies and depends on a number of factors. According to Mittasova [16], the amount of global solar radiation available depends on factors like location, time of the year, and atmospheric conditions. As variation of so- 
lar radiation is the single most important factor affecting climate, seasonal variation of solar radiation is very important as well in estimating global solar radiation.

For this study, the geographical factors, latitude and longitude, are considered in modelling global solar radiation simply because every location on earth receives sunlight at least part of the year and the amount of solar radiation that reaches any spot on the earth's surface basically varies according to the geographical location and season. Both latitude and longitude are the means by which the position of any place on the earth's surface are determined and their attributes directly observed.

\section{Material and Methodology}

In this section, basic issues relating to the base and methodology of the study are considered. The domain for this application encompasses all the nations of the world, but the African continent has been selected for illustrating the methodology adopted.

\subsection{The African Continent}

Geographically, Africa lies between latitudes $37^{\circ} \mathrm{N}$ and $35^{\circ} \mathrm{S}$, and between longitudes $52^{\circ} \mathrm{E}$ and $17^{\circ} \mathrm{W}$. The continent comprises of 54 independent countries. In assessing climate features of geographical locations and their seasons in this study, the African continent was subdivided into the five approved subregions, namely, North Africa, West Africa, Central Africa, East Africa and Southern Africa. These zones are shown in Figure 1.

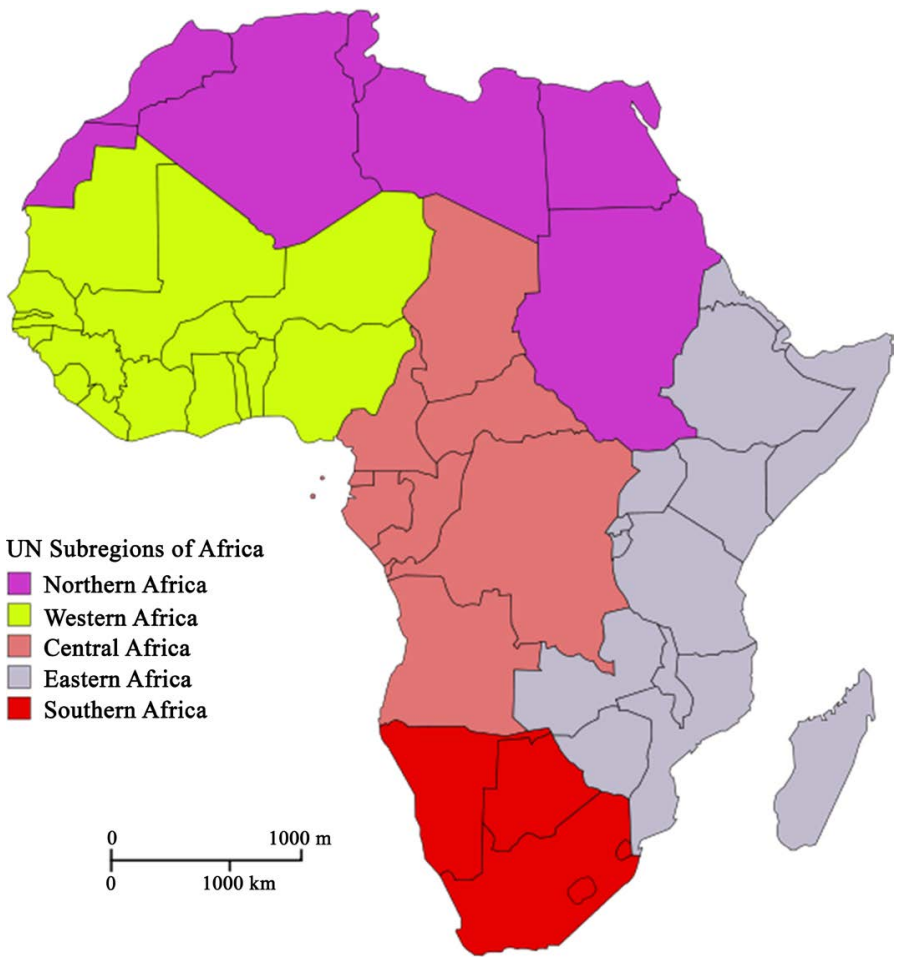

Figure 1. Map of Africa [17]. 
North Africa is characterized by the Mediterranean climate at the coast and a large desert area in the south where temperatures are hottest. The seasons observed in the subregion are Spring (March-May), Summer (June-September), Autumn (October-November) and Winter (December-February) [18].

The West African subregion is influenced by the inter-tropical divergence. The rainy season in coastal areas is generally observed from the end of April to July with a second and shorter rainy season in September and October. Further inland, only one rainy season is observed from June to September.

Central Africa is one of the wettest parts of the continent. Three peak rainfall periods are experienced in the region, namely, March-May, July-September and October-December.

The climate in East Africa is typically equatorial with high temperatures year round and little seasonal variation especially close to the Equator. There are two short rainy seasons: one around April-June, and the other from October-December.

The Southern Africa subregion is mainly characterized by a wet and hot season from October to March (Summer), and a cool and dry season from April to September (Winter).

\subsection{Methodology}

There are largely two broad categories of techniques, with varying structures, available for developing mathematical models; these are the theoretical and empirical modelling [19]. The theoretical approach is based on laws and regulations which have been verified, and such a model can be used to estimate real life scenarios with significant confidence.

The empirical technique, on the other hand, makes use of previous measurements that reveal relationships between the variables. Such relationships are to be utilized to make some predictions. Empirical modeling was, therefore, adopted for use in this study since the theoretical framework for forming some relationship between the factors is not available.

To generate the empirical data needed for this study, latitudes to the north of the Equator are regarded as positive while those to the south of the Equator are taken as negative. Similarly, longitudes to the east of the Greenwich Meridian are assigned positive values while negative values are attached to longitudes to the west of the Greenwich Meridian.

Interannual monthly average daily insolation for the period between 1996 and 2017 from the database of the National Aeronautics and Space Administration (NASA) were obtained and processed to average global solar radiation, being guided by the information from the World Meteorological Organization on the climatic conditions and seasons, over the entire five subregions in Africa.

Locations were carefully selected within each of the subregions and the average global solar radiation were collated via the Power Data Access Viewer [20]. The collated data are graphical represented in Figures 2-6. 
The method of interpolation was adopted in developing global solar radiation models for any geographical location in the subregions. Figure 7 describes the processes and tasks involved in obtaining the proposed models.

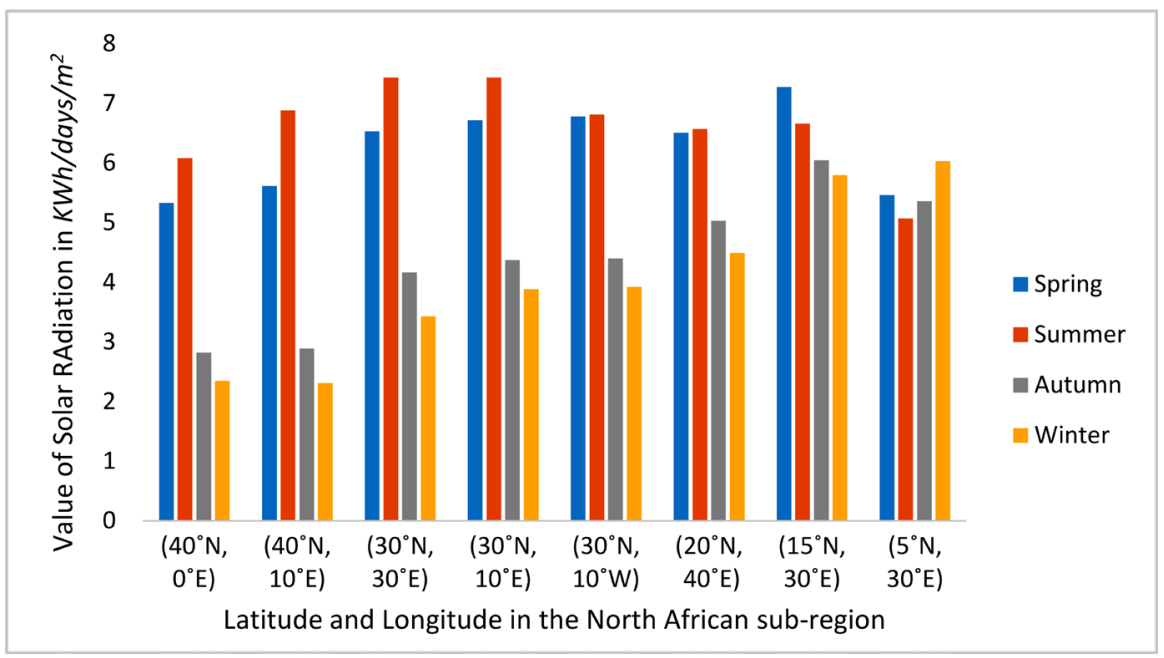

Figure 2. Global solar radiation data for selected locations in North Africa.

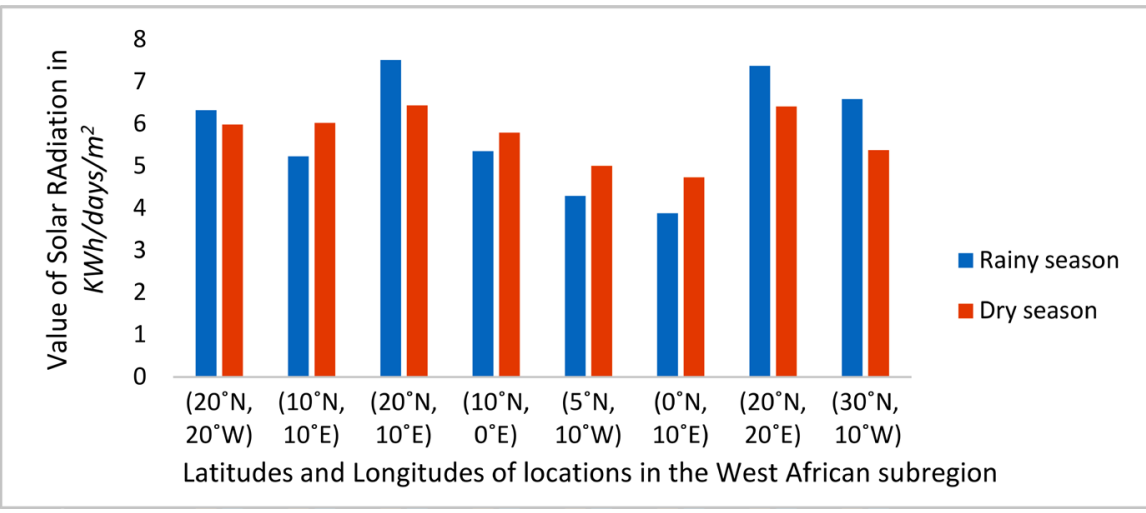

Figure 3. Global solar radiation data for selected locations in West Africa.

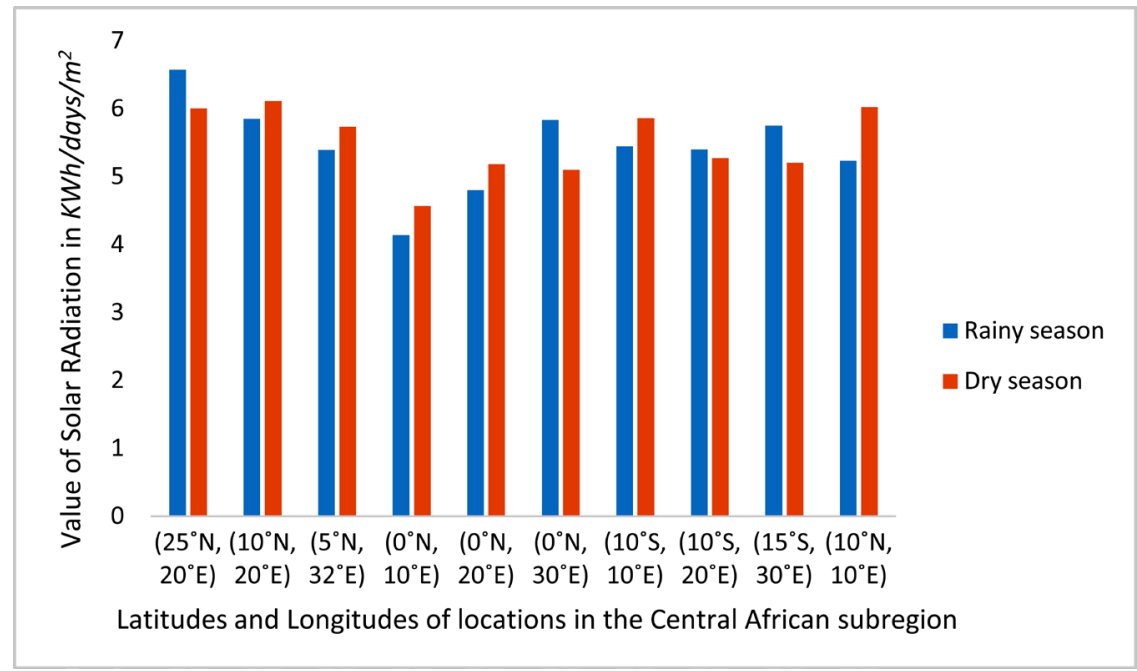

Figure 4. Global solar radiation data for selected locations in Central Africa. 


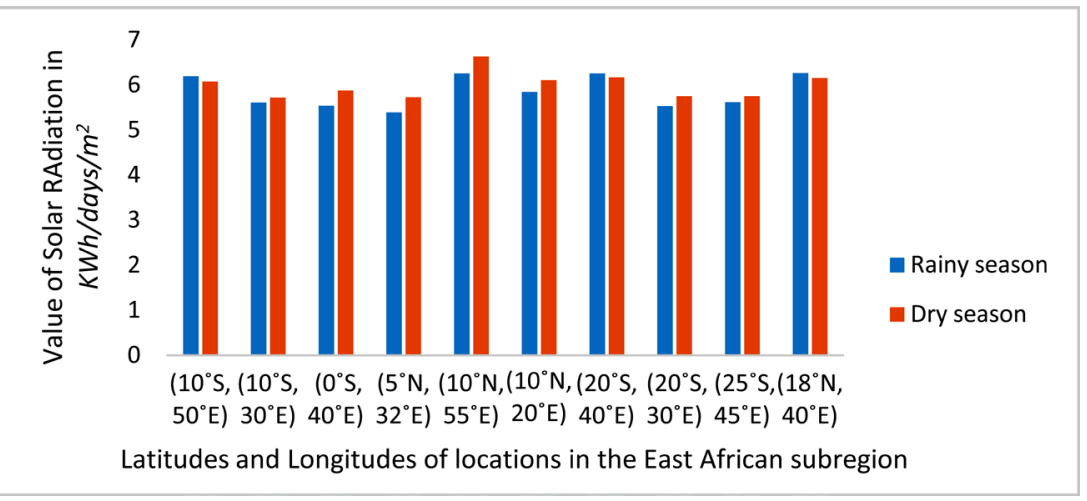

Figure 5. Global solar radiation data for selected locations in East Africa.

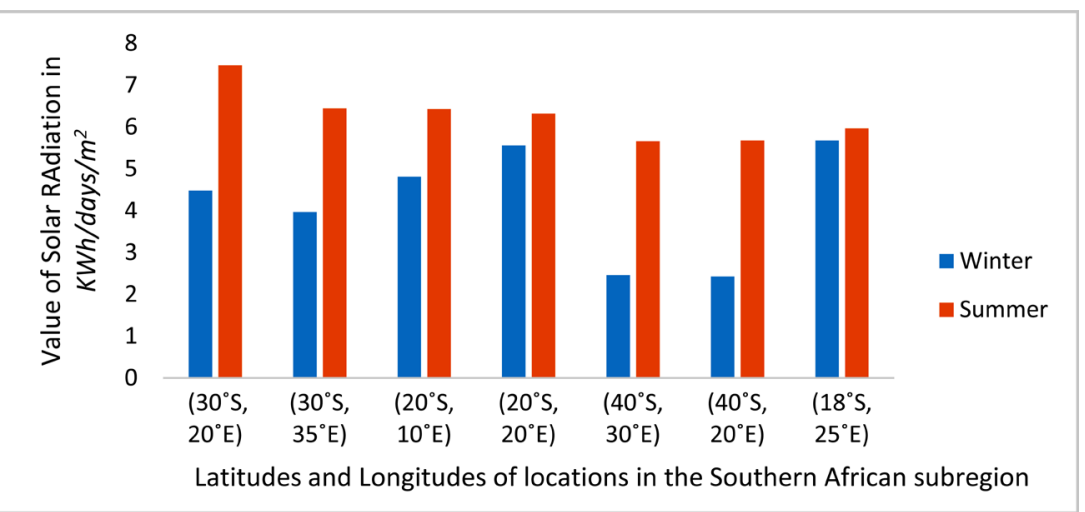

Figure 6. Global solar radiation data for selected locations in Southern Africa.

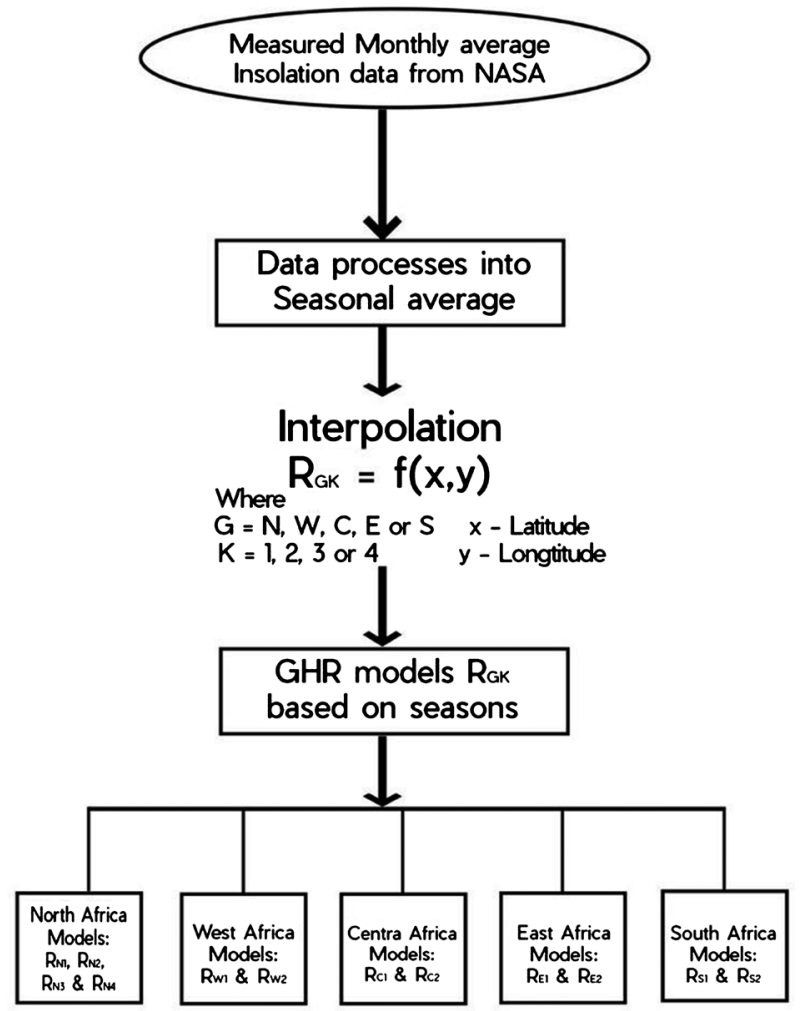

Figure 7. Flow chart for methodology in the present study. 


\section{Results}

\subsection{Empirical Models}

In handling discrete data, with the intent of generating a predictive tool, it is customary to apply the concept of interpolation. Polynomials are commonly used for interpolation because they are easy to evaluate, differentiate and integrate [21].

\section{Empirical Global Solar Radiation Models}

The Wolfram mathematical software is a typical tool that is designed for constructing interpolants that are capable of evaluating a function and its derivatives at specific interpolation points [22]. With the data in Figures 2-6, the software was used to generate two-dimensional interpolating polynomials in variables $X$ and $y$, where $x$ and $y$ respectively denote the latitude and longitude components of the location. Incorporating the different seasons into each subregion, the following empirical models were obtained.

\section{North Africa:}

$$
\begin{aligned}
R_{N 1}= & 12.0388+0.12609 x-0.0182203 x^{2}+0.000271859 x^{3} \\
& -0.28832 y+0.0141218 x y-0.000153931 x^{2} y-0.000148864 y^{2} \\
R_{N 2}= & 2.5493+0.509602 x-0.0156812 x^{2}+0.000128806 x^{3} \\
& +0.0604844 y-0.0059339 x y+0.00016503 x^{2} y-0.000774431 y^{2} \\
R_{N 3}= & 11.1332-0.0107351 x-0.0136715 x^{2}+0.00021861 x^{3} \\
& -0.232581 y+0.0127298 x y-0.000167089 x^{2} y-0.000233522 y^{2} \\
R_{N 4}= & 10.573-0.0702876 x-0.00987517 x^{2}+0.000162251 x^{3} \\
& -0.157611 y+0.00880711 x y-0.000120762 x^{2} y-0.000516666 y^{2}
\end{aligned}
$$

where $R_{N 1}, R_{N 2}, R_{N 3}, R_{N 4}$ denote the seasonal global radiation for the four seasons in North Africa, namely, Spring, Summer, Autumn, and Winter. The domain of each of the four models is

$$
D_{N}=\{(x, y): 5 \leq x \leq 40,-10 \leq y \leq 40\} .
$$

\section{West Africa:}

$$
\begin{aligned}
R_{W 1}= & 3.96376+0.0228769 x+0.0158509 x^{2}-0.000421256 x^{3} \\
& +0.00587765 y-0.00199591 x y+0.00015084 x^{2} y-0.00134874 y^{2} \\
R_{W 2}= & 4.77514+0.0707062 x+0.0057673 x^{2}-0.000265387 x^{3} \\
& +0.00052142 y+0.00487346 x y-0.00021861 x^{2} y-0.000433544 y^{2}
\end{aligned}
$$

where $R_{W 1}$ and $R_{W 2}$ denote the seasonal global radiation, for the two seasons in West Africa, in the domain $D_{W}=\{(x, y): 0 \leq x \leq 30,-20 \leq y \leq 20\}$.

Central Africa:

$$
\begin{aligned}
R_{C 1}= & 2.94796-0.0182047 x+0.0158222 x^{2}-0.000301331 x^{3} \\
& +0.144672 y+0.00399308 x y-0.000377977 x^{2} y \\
& -0.00260641 y^{2}-0.0000226986 x y^{2}
\end{aligned}
$$




$$
\begin{aligned}
R_{C 2}= & 3.84798-0.0645648 x+0.0224157 x^{2}-0.000258392 x^{3} \\
& +0.0771062 y+0.0131217 x y-0.00086798 x^{2} y \\
& -0.000516168 y^{2}-0.000325 x y^{2}
\end{aligned}
$$

where $R_{C 1}$ and $R_{C 2}$ denote the seasonal global radiation for the two seasons in the domain

$$
D_{C}=\{(x, y):-15 \leq x \leq 25,10 \leq y \leq 32\} .
$$

\section{East Africa:}

$$
\begin{aligned}
R_{E 1}= & -2.88039+0.450858 x+0.00583204 x^{2}+0.000164107 x^{3} \\
& +0.622334 y-0.0236714 x y-0.0000878816 x^{2} y \\
& -0.0155337 y^{2}+0.000275662 x y^{2}+0.00013103 y^{3} \\
R_{E 2}= & 1.27347+0.350915 x+0.00404128 x^{2}+0.0000642684 x^{3} \\
& +0.313112 y-0.0183783 x y-0.0000775406 x^{2} y \\
& -0.0074416 y^{2}+0.0002264 x y^{2}+0.0000622583 y^{3}
\end{aligned}
$$

where $R_{E 1}$ and $R_{E 2}$ denote the seasonal global radiation in the valid domain

$$
D_{E}=\{(x, y):-25 \leq x \leq 18,30 \leq y \leq 55\} .
$$

\section{Southern Africa:}

$$
\begin{aligned}
R_{S 1}= & 3.40494-0.0490626 x-0.00285428 x^{2}+0.0000219348 x^{3} \\
& +0.196849 y-0.00132395 x y-0.00491978 y^{2} \\
R_{S 2}= & 25.7696+2.42097 x+0.0954067 x^{2}+0.00122414 x^{3} \\
& +0.0208147 y-0.00461178 x y-0.00414814 y^{2}
\end{aligned}
$$

where $R_{S 1}$ and $R_{S 2}$ denote the seasonal global radiation for the two seasons in Southern Africa, together with their domain $D_{W}=\{(x, y):-40 \leq x \leq-18,10 \leq y \leq 35\}$.

The generalized form of the models given by Equations (1)-(5) is

$$
R_{G k}=a+b x+c x^{2}+d x^{3}+e y+f x y+g x^{2} y+h y^{2}+i x y^{2}+j y^{3}
$$

where $a, b, c, d, e, f, g, h, i, j \in \mathrm{R},-2.89<a<25.77,-0.08<b<2.43$, $-0.02<c<0.1,-0.0005<d<0.002,-0.29<e<0.7,-0.03<f<0.02$, $-0.0009<g<0.0002, h \leq 0,-0.0003<i<0.004, j \geq 0 ; G=N, W, C, E$ or $S$ and $k=1,2,3$ or 4 .

\subsection{Analysis of the Models}

Contributions of location components $x$ and $y$ in determining the average seasonal global horizontal insolation in subregions of Africa as shown in Table 1 were obtained by adopting the following procedure:

Step 1: Divide each model $R_{G k}$ through by its least coefficient.

Step 2: Using the domain of definition $D_{G}$, neutralize $x$ and subsequently $y$ in $R_{G k}$.

Step 3: Determine the dominant location component and its percentage contribution. 


\subsubsection{Prediction}

Mathematical models (1)-(5) were also used to predict values of global solar radiation for the latitude and longitude coordinates of selected places in each subregion. The results for the predicted and actual values are as shown in Figures 8-12.

The coefficients of correlation [23] between the predicted and actual values in Figures 8-12 are as presented in Table 2.

\subsubsection{Result Comparison}

The location-based models by Gopiathan [24] and Glover [25] together with Ansgtrom based one, by Rietveld [26], were compared at some selected locations and the result displayed in Figure 13.

Table 1. Contributions of variables in $R_{G k}$.

\begin{tabular}{cccccc}
\hline \multirow{2}{*}{ Region } & Domain $D_{N}$ & Model & \multicolumn{2}{c}{$\%$ contribution } & $\begin{array}{c}\text { Dominant } \\
\text { component }\end{array}$ \\
\cline { 4 - 5 } North Africa & $5 \leq x \leq 40$ & $R_{N} 1$ & 87.23 & 12.77 & $X$ \\
& $-10 \leq y \leq 40$ & $R_{N} 2$ & 63.60 & 36.4 & $X$ \\
& & $R_{N} 3$ & 60.99 & 39.01 & $X$ \\
West Africa & $0 \leq x \leq 30$ & $R W 1$ & 68.49 & 31.51 & $X$ \\
& $-20 \leq y \leq 20$ & $R W 2$ & 50.86 & 49.14 & $X$ \\
Central Africa & $-15 \leq x \leq 25$ & $R_{C} 1$ & 72.93 & 27.07 & $X$ \\
& $10 \leq y \leq 32$ & $R_{C} 2$ & 67.21 & 32.79 & $X$ \\
East Africa & $-25 \leq x \leq 18$ & $R_{E} 1$ & 57.31 & 42.69 & $X$ \\
& $30 \leq y \leq 55$ & $R_{E} 2$ & 57.74 & 40.26 & $X$ \\
Southern Africa & $-40 \leq x \leq-18$ & $R S 1$ & 54.75 & 45.25 & $X$ \\
& $10 \leq y \leq 35$ & $R S 2$ & 72.41 & 27.53 & $X$ \\
\hline
\end{tabular}

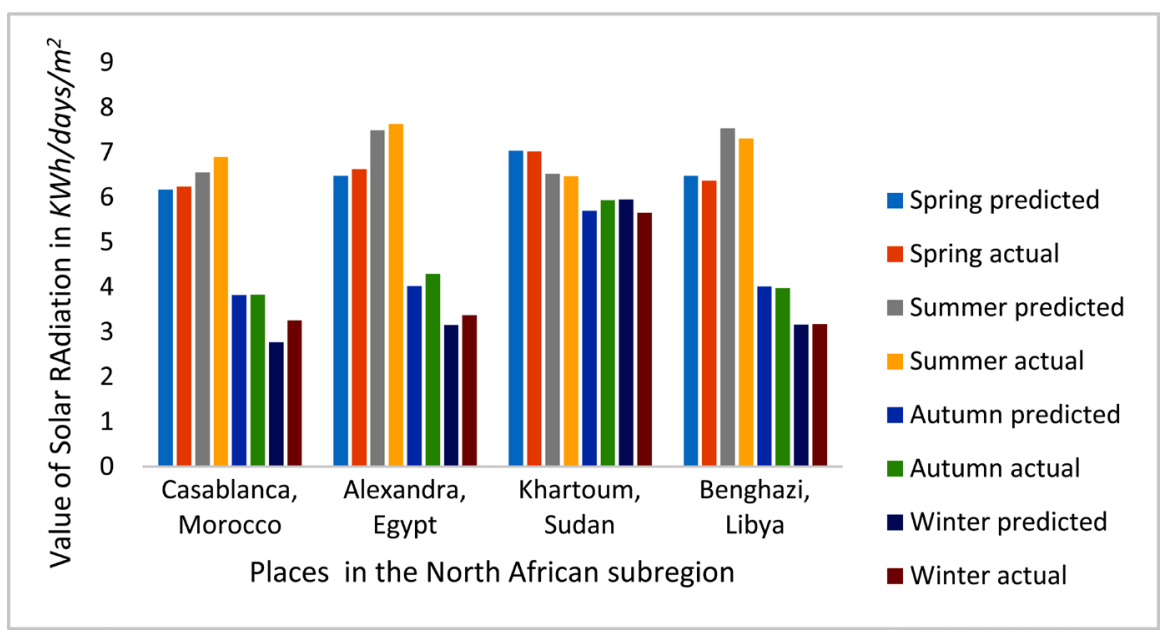

Figure 8. Predicted and actual values of global solar radiation at selected places in North Africa. 


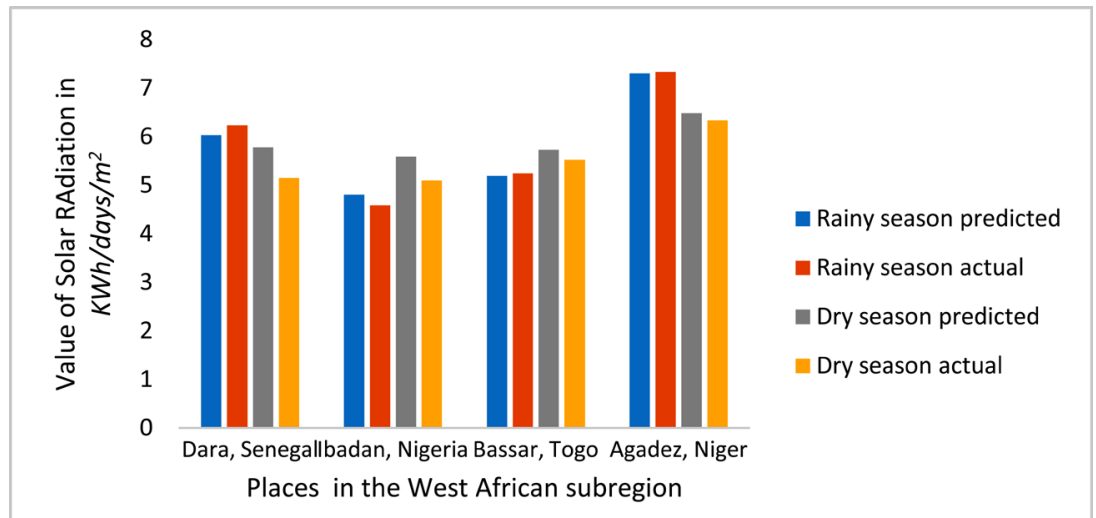

Figure 9. Predicted and actual values of global solar radiation at selected places in West Africa.

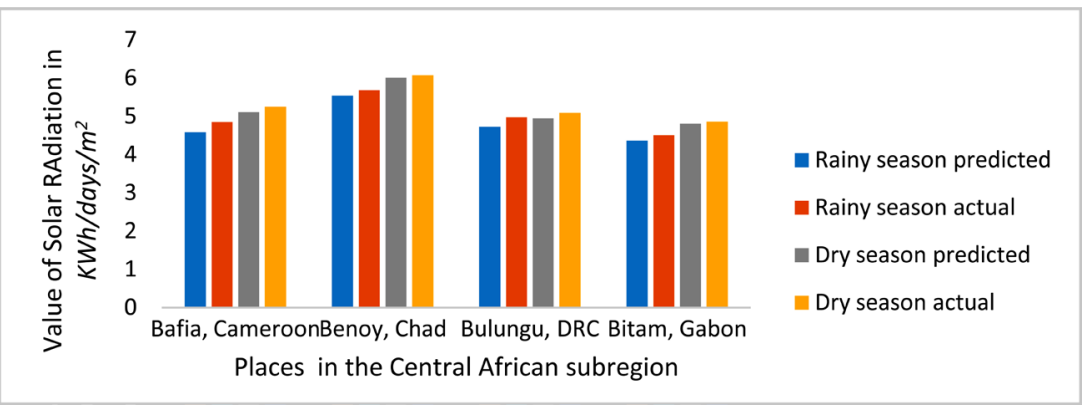

Figure 10. Predicted and actual values of global solar radiation at selected places in Central Africa.

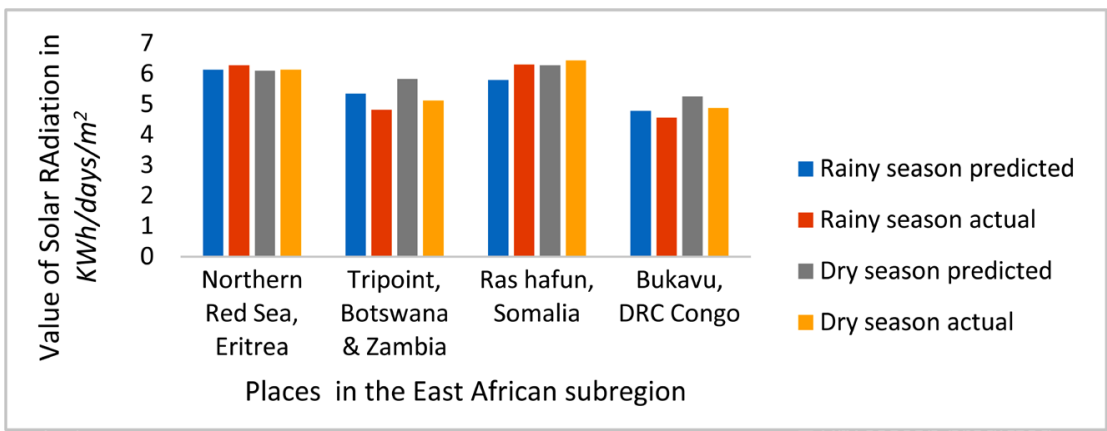

Figure 11. Predicted and actual values of global solar radiation at selected places in East Africa.

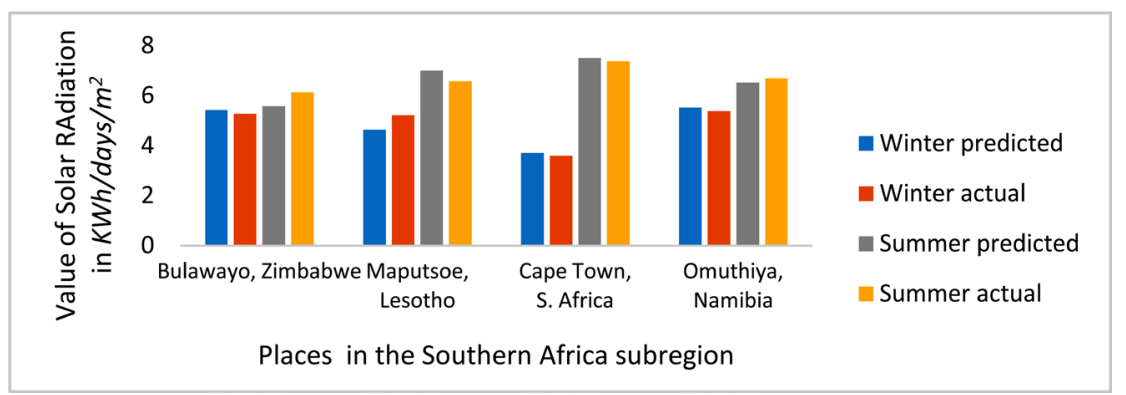

Figure 12. Predicted and actual values of global solar radiation at selected places in Southern Africa. 
Table 2. Correlation coefficients between predicted and actual global solar radiations.

\begin{tabular}{cc}
\hline Models & Correlation coefficient \\
\hline$R_{N 1}$ & 0.954699 \\
$R_{N 2}$ & 0.901375 \\
$R_{N 3}$ & 0.990823 \\
$R_{N 4}$ & 0.990259 \\
$R_{W 1}$ & 0.992251 \\
$R_{W 2}$ & 0.948107 \\
$R_{C 1}$ & 0.991575 \\
$R_{C 2}$ & 0.996414 \\
$R_{E 1}$ & 0.924941 \\
$R_{E 2}$ & 0.911480 \\
$R_{S 1}$ & 0.911290 \\
$R_{S 2}$ & 0.900962 \\
\hline
\end{tabular}

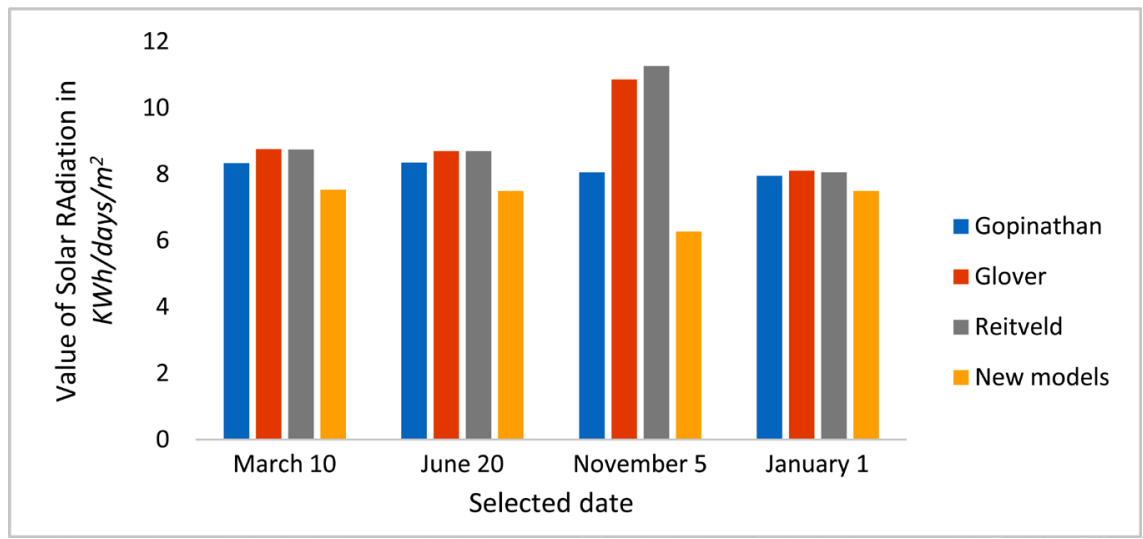

Figure 13. Comparison of global solar radiation models.

\section{Discussion and Conclusion}

\subsection{Discussion}

The resulting models for global solar radiation in the five subregions of Africa, as shown in Equations (1)-(5), indicate that each of the models is unique and in line with reality, since solar radiation is always available even during the harshest winter or most flooding rainy season.

An important aspect of empirical modelling is to build models that generalize well, and this is central to the success of a model to be fit for use as a predictor. This capacity has been demonstrated by means of the high level of predictability (with correlation coefficients not less than 0.9) achieved with the new models.

The factor analysis indicates that in determining the seasonal global solar radiation for Africa's subregions, latitude played the major role with an overall contribution of $63.78 \%$. The dominance of latitude as a component of the location factor buttresses some aspect of the information in [27]. This result implies that 
a simpler model depending only on latitude can be fashioned to measure seasonal variation of global solar radiation all the year round.

A comparison of the global solar radiations generated and graphically illustrated in Figures 8-12 indicate that the new empirical models made very reliable predictions as evidenced by the close agreement between the predicted and actual values of global solar radiation. From Figure 13, the results compare favourably with those obtained using Gopinathan, Glover and Reitveld models. Rietveld method consistently produced the largest outputs while the outputs of the new models were consistently the least. This implies that the proposed method is the best of the four methods for estimating global solar radiation for intended practical purposes.

Another merit is that the domain of application, i.e. the subregions of the African continent, is the largest found in the literature.

\subsection{Conclusions}

The mean daily global solar radiation has been considered in this study as dependents of locational and seasonal factors while the data for the African continent were used for illustrating the methodology adopted. The new models obtained were presented in closed form for the five subregions of Africa.

The novelty in this paper is that accurate, reliable and computationally less burdensome empirical models with a few input factors were developed for use as predictive tools in estimating global solar radiation derivable for any location. This study also affirms the latitude as the dominant locational factor. In addition, the domain of application in the study is the largest so far.

Finally, the new models featured optimal performance in respect of estimating global solar radiation for any practical application.

\section{Conflicts of Interest}

The authors declare no conflicts of interest regarding the publication of this paper.

\section{References}

[1] International Energy Agency (2011) World Energy Outlook 2011. OECD Publishing, Paris.

[2] Lewis, N.S., Crabtree, G., Nozik, A.J., Wasielewski, M.R., Alivisatos, P., Kung, H., Tsao, J., Chandler, E., Walukiewicz, W., Spitler, M., Ellingson, R., Overend, R., Mazer, J., Gress, M., Horwitz, J., Ashton, C., Herndon, B., Shapard, L. and Nault, R.M. (2005) Basic Research Needs for Solar Energy Utilization. Report of the Basic Energy Sciences Workshop on Solar Energy Utilization, 1-8. https://doi.org/10.2172/899136

[3] George, E.P. and Draper, N.R. (1987) Empirical Model-Building and Response Surfaces. Wiley, Hoboken, 424

[4] Ekici, C. (2019) Total Global Solar Radiation Estimation Models and Applications: A Review. International Journal Innovative Technology and Inter-Disciplinary Sciences, 2, 212-228. 
[5] Muneer, T. and Kambezidis, H. (1997) Solar Radiation and Daylight Models for the Energy Efficient Design of Buildings. Architectural Press, Oxford.

[6] Latunde, T., Bamigbola, O.M. and Aderinto, Y.O. (2016) Sensitivity of Parameters in an Optimal Control Model of the Electric Power Generating System. Ilorin Journal of Computer Science and Information Technology, 1, 54-69.

[7] Bradford, T. (2006) Solar Revolution: The Economic Transformation of the Global Energy Industry. Global Environmental Politics, 7, 147-148. https://doi.org/10.1162/glep.2007.7.4.147

[8] Connelly, J.N., Bizzarro, M., Krot, A.N., Nordlund, A., Wiedlandt, D. and Ivanova, M.A. (2012) The Absolute Chronology and Thermal Processing of Solid in the Solar Protoplanetary Disk. Science, 338, 651-655. https://doi.org/10.1126/science.1226919

[9] Sun, Z., et al. (2014) Parametrization of Instantaneous Global Horizontal Irradiance: Clear Sky Component. Quarterly Journal of the Royal Meteorological Society, 140, 267-280. https://doi.org/10.1002/qj.2126

[10] Angstrom, A. (1924) Solar and Atmospheric Radiation. Quarterly Journal of the Royal Meteorological Society, 50, 121-126. https://doi.org/10.1002/qj.49705021008

[11] Falayi, E.O., Adepitan, J.O. and Rabiu, A.B. (2008) Empirical Models for the Correlation of Global Solar Radiation with Meteorological Data for Iseyin, Nigeria. International Journal of Physical Sciences, 3, 210-216.

[12] Akpabio, L.E., Udo, S.O. and Etuk, S.E. (2005) Modeling Global Solar Radiation for a Tropical Location: Onne, Nigeria. Turkish Journal of Physics, 29, 63-68.

[13] Kolebaje, O.T. and Mustapha, L.O. (2012) On the Performance of Some Predictive Models for Global Solar Radiation Estimates in Tropical Stations: Port Harcourt and Lokoja. African Review of Physics, 7, 145-163.

[14] Soufi, A., Chermitti, A., Mostafa, B.M. and Zehor, A. (2014) Investigating the Performance of Chosen Models for the Estimation of Global Solar Radiation on the Horizontal Surface: A Case Study in Terny Hdiel, Tlemcen of Algeria. International Journal of Engineering Science Technologies, 7, 45-49. https://doi.org/10.25103/jestr.073.07

[15] Coulibaly, O. and Ouedoraogo, A. (2016) Correlation of Global Solar Radiation of Eight Synoptic Stations in Burkina Faso Based on Linear and Multiple Linear Regression Methods. Journal of Solar Energy, 2016, Article ID: 7870907. https://doi.org/10.1155/2016/7870907

[16] Mittasova, H., Alvarez, J. and Allen, L. (2011) Estimating Monthly Solar Radiation in South Central Chile. Chilean Journal of Agricultural Research, 71, 601-609. https://doi.org/10.4067/S0718-58392011000400016

[17] Wikipedia. https://en.wikipedia.org/wiki/List-of-regions-of-Africa

[18] World Meteorological Organization (2015) The Climate in Africa: 2013, WMO Publication. http://www.wmo.int/pages/prog/wcp/wcdmp/documents/1147-EN.pdf

[19] Flood, I. (2009) Empirical Modeling: Current and Emerging Techniques-Tutorial. Research Foundation Professor, Rinker School, College of design, Construction and Planning, University of Florida, Gainesville, 1-35.

[20] Yates, T. (2017) Surface Solar Energy Resources and Meteorological Conditions, Solar and Terminological Data Sets from NASA Research for the Support of Renewable Energy, Building Energy and Agricultural Needs (Data Access Viewer, DAV). https://power.larc.nasa.gov

[21] Wahab, M.A. (2017) Interpolation and Extrapolation. Warburgher: University of Pardeborn. 
[22] Wolfram Research Inc. (2016) System Modeller, 11.0.1.0.

[23] Schober, P., Boer, C. and Schwarte, L. (2018) Correlation Coefficients: Appropriate Use and Interpretation. Anesthesia \& Anesthesia, 126, 1763-1768.

https://doi.org/10.1213/ANE.0000000000002864

[24] Gopinathan, K.K. (1988) A General Formula for Computing the Coefficients of the Correlations Connecting Global Solar Radiation to Sunshine Duration. Solar Energy, 41, 499-502. https://doi.org/10.1016/0038-092X(88)90052-7

[25] Glover, J. and McCulloch, S.G. (1958) The Empirical Relation between Solar Radiation and Hours of Sunshine. Quarterly Journal of the Royal Meteorological Society, 84, 172-175. https://doi.org/10.1002/qj.49708436011

[26] Rietveld, M. (1978) A New Method for Estimating the Regression Coefficients in the Formula Relating Solar Radiation to Sunshine. Agricultural Meteorology, 19, 43-52. https://doi.org/10.1016/0002-1571(78)90014-6

[27] https://sunmetrix.com/top-five-factors-determining-solar-energy-potential 